\title{
Socio-cultural Factors and Practices Affecting the Girl Child among the Annang People of Akwa Ibom State
}

\author{
Magdalene Agbor Igbolo ${ }^{1}$, Frances Umari Ejue ${ }^{2}$ \\ ${ }^{1}$ Department of sociology, Faculty of Social Science, University of Abuja, Abuja, Nigeria \\ ${ }^{2}$ Department of sociology, Faculty of Social Science, Federal University Lafia, Nasarawa State, Nigeria \\ Correspondence: Magdalene Agbor Igbolo, PhD, Department of sociology, Faculty of Social Science, University of \\ Abuja, Abuja, Nigeria.
}

Received: October 12, 2016

Accepted: November 17, 2016 Online Published: November 23, 2016

doi:10.11114/smc.v4i2.2007

URL: http://dx.doi.org/10.11114/smc.v4i2.2007

\begin{abstract}
Household discriminatory practices on the girl-child have drawn attention worldwide due to deep-rooted socio-cultural beliefs, values and practices. Despite extensive empirical evidence in literature there is a dearth of studies in Nigeria in particular. This study examined the socio-cultural factors and practices affecting the girl-child among the Annang, an ethnic group in Akwa-Ibom State-Nigeria. The study adopted the Weber's social action theory as theoretical framework to provide theoretical orientation to the issue investigated. A multi-methodological approach was adopted in generating data. A household survey was conducted among 100 respondents which comprised of pairs of fathers/male-children and mothers/female-children. A four-staged sampling technique was used to purposively select 3 Enumeration Areas (EAs). Structured questionnaires elicited information on cultural construction of girlhood, familial roles and household practices from both adults and boy and girl-children. Four Focus Group Discussions (FGDs) and IDIs which centred on gender socialization, gender relations, household practices, and socio-cultural factors were conducted among adults males and females as well as male and female-children. Indepth interviews were also conducted with religious leaders, traditional rulers, as well as male and female community leaders. Quantitative data were analyzed using descriptive statistics. The qualitative data employed content analysis as well as thematic narratives of participants and key informants views and responses. Adult respondents' mean age was $40.3 \pm 10.0$ years, $98.1 \%$ were married, and $81.7 \%$ were farmers. The mean age for boys and girl-children was 13.5 \pm 3.2 years. Majority of the respondents were rural dwellers (82.0\%). Majority of respondents (97.1\%) opined that the status of the girl-child was very low relative to the boy-child. About $99 \%$ affirmed that girl-children were disadvantaged with regard to opportunities and privileges. The girl-child faced household discriminatory practices in domestic work assignment (79.0\%), education (78.4\%) and restrictive food taboos (32.2\%). Significant others approved such practices. About $67 \%$ of girl-children perceived the practices as acceptable to the Annang people. The qualitative data identified socio-cultural factors such as conception of gender roles, gender socialization, son preference, cultural construction of girlhood, and valuation of the girl-child, decision-making, gender stereotyping among others engendered these practices. Cultural construction of girlhood was largely defined by the respondents' societal notions on femininity. Household discriminatory practices among the Annang people, was largely due to socio-cultural factors and practices. Therefore, serious attention should be given to community mobilization and sensitization to address the socio-cultural factors and harmful practices which limit the empowerment of the girl-child.
\end{abstract}

Keywords: socio-cultural factors; girl child, empowerment, education, harmful traditional practices

\section{Introduction}

The last two centuries, which have been viewed as the age of modernity, have been essentially structured by varying historical processes. Significantly, gender and racial categories emerged during this period as two fundamental instruments for exploiting people and stratifying societies (Oyewunmi, 2004). Euro centric attitude, being a hallmark of the ensuing modernity gave impetus to the creation and imposition of Eurocentric/American cultural hegemonies throughout the world. Consequently, male-gender privilege as an essential part of European ethos became enshrined in the culture of modernity. In the quest of comprehending African realities, and indeed, state of gender relations in Nigeria, this global context for knowledge production has become imperative. 
At the advent of colonialism (which came with the introduction of Christianity), rigid binaries about everything including gender perceptions were imposed on the African mind. Consequently, the woman's role has come to be limited to sexual and commercial labour; satisfying the sexual needs of men, working in the fields, carrying loads, tending babies and preparing food (Alabi, Bahal \& Alabi, 2012). Thus, the disempowering colonial ideology of domesticity as espoused by the practice of 'housewification' provided the springboard for women's educational imbalance in parts of Africa (Gaidzwanwa, 1992). As such, the attainment of overall human development in Nigeria is being obliterated by this unevenness in educational accessibility across gender categories (Abdullahi, 2000).

There is no doubt that societal recognition of the value of education has been displaced, paving the way for ignorance and the people's deplorable condition of education, particularly that of the girl-child. This situation arose as a result of several reasons, among which are socio-cultural, ignorance, economic stagnation characterized by pervasive poverty which has virtually weakened all sectors of development, especially the education sector, and above all inefficient and ineffective implementation of the national and state government policies on education. These impediments contributed to poor school enrolment particularly that of the girl-child who is considered not necessarily relevant to pursue formal education in the traditional social set up.

For instance, socio-cultural factors are significant in parental and family decisions on whether to invest in girl-child education. Pervasive gender ideologies at the household and community levels always favour boys over girls and promote differential educational opportunities and outcomes. Socio-cultural believes and custom influence decision to enroll girls in schools, decision to withdraw them from schools and decision to drop out of school and indeed, their academic performance as well as grade level attainment. Also, the socio-cultural expectation of girls and the priority accorded to their future roles as mothers and wives have a strong negative bearing on their formal education. The girl-child is discriminated by virtue of her sex, the structure of the society, its values, traditions and institutions all have an in-built discrimination against women. The assigning of different expectations to male or female has made the traditional society in the past years to believe that it is not natural for a female child to be educated. As such, the illiterate parents prefer to have their female children doing some domestic work at home.

Traditional beliefs to some extent hamper girl-child education. It ranges from the fact that girls do not carry on the family name like boys. If at all they send their children, it is limited to the male children who according to such parents would occupy their place in the case of death. As such, every available means is used to train the boys at the detriment of girls because of their important role in protecting the "family name". In addition, some girl-children are withdrawn from school or denied access to higher education because of the belief that the higher the girls educational attainment/qualification the lower her chances of finding a suitable husband.

Poverty and the impoverished condition of the citizenry serve as a barrier to girl-child education. Most mothers preferred street hawking and early marriage than sending their wards to school. In the same vein, family background of the girl determines her chance of attending school. The more educated a parent, the more favourable his/her attitudes to education. Further to this, in most polygamous homes, boys are usually given considerations whenever there are scarce resources for the training of the children. Sometimes, an intelligent girl is deprived of opportunity to go to school while allowing a less intelligent or less ambitious boy to go to school. Also, the input of the girl-child in the family income is so high that it becomes economically unwise to allow such a child to pursue western type of education. Such income could therefore, be generated through hawking food items. The situation led girls between the ages of thirteen to fifteen are falling headlong into marriage and thereafter begin to face the challenges of child birth. One, they are denied the opportunity of formal education as they could not have any solid economic base or resources. With little or no education, capital, access to credit facilities, they are subordinated perpetually to their husbands for almost everything, even the way they think and behave. This does not only affect the young women or rather the girl-children but also their offspring who due to the collapse of social and religious welfare services, are dumped with their unsecured mothers. These children are often faced with the problem of proper parental guidance. As a result, they could join some urban gangs or go into crime due to the nature of their upbringing. There are also the political and institutional related factors which serve as the major impediment towards the development of the girl-child education, thereby increasing the gender gap.

The plight of the girl-child gained the attention of the global community in the 1990s. She has claimed a place of prominence on the human development agenda as a result of her social conditions and well-being. It was the Fourth World Conference on Women held in Beijing in 1995 that identified the girl-child as the $12^{\text {th }}$ critical area of concern. A more recent report on the appraisal of the Beijing Platform for Action, BPFA $15^{+}(1995-2009)$ on Africa noted that despite significant progress on integrating the Rights of the Child into domestic law through legislative and constitutional reforms in most African countries, discriminatory household practices still persists against the girl-child (Ogidi, 1997; Aderinto, 1999). Most importantly, quite a number of studies suggest that household discriminatory practices still persist against the girl-child as a result of deep-rooted socio-cultural beliefs, social norms, values and practices (Jutting and Morrison, 2005a; 2005b; Lundberg,2005). This underscores the need to explore the factors and 
practices that engenders household discriminatory practices against the girl-child. Moreover, due to variations in culture, the socio-cultural factors and the contexts under which these practices persist vary from region to region. It is against this backdrop that the current study is set to examine the socio-cultural factors and practices affecting the girl-child among the Annang people of Akwa-Ibom State, Nigeria.

\subsection{The Research Problem}

Arguably, the negative outcomes of household practices on the girl-child have remained invisible because most often the tendency has been to subsume the girl-child under the category of "women". Thus, the invisibility of the girl-child was often the result of an overstatement on and the homogenising of "woman" as a category (Punelakar, 1995; Reddy, 2009). Currently, the girl-child has been a focus of anthropological and sociological inquiry. There has been a growing scholarship on the girl-child in Asia and as such, many rather view the problems confronting the girl-child more as an Asian rather than an African phenomenon (Janseen 2006). Also, there are relatively few studies on the socio-cultural factors that engendered discriminatory practices against the girl-child in Africa, and Nigeria in particular (Aina \& Abdullahi, 1995).

There has been a new focus on household members as separate individuals in view of the fact that different members face different opportunities and constraints depending on their status. Interestingly, such a focus would provide insights on high risk groups among members of the household (Kapur, 2005 Punalekar, 1995). Thus, there has been an increasing recognition that boys and girls are treated differently throughout their lives, and most often gender differences have been associated with cultural perceptions of appropriate male and female responsibilities (Plan, 2007). Likewise, Anyanwu (1995) asserted that the patterns of parental care accorded children are largely influenced by socio-cultural factors and the attitude of the society. Based on the foregoing, studies have confirmed that the girl-child is more vulnerable and more likely to face household discriminatory practices in education, domestic work assignment, food allocation and in health related issues (Aderinto, 1999; Rufai \& Ogidi, 2006).These practices affects the well-being of the girl-child and limits the capacities and empowerment of the girl-child.

A number of studies (Pande \& Malhotra, 2006) indicated that there are complexities of types and levels of situation confronting the girl-child. Based on the foregoing, Kapur (2005) suggests that dealing with the problems confronting the girl-child would require "a multipronged, multidisciplinary, multiphase, multi-dimensional and holistic approach". The present study keys into this observation given the dearth of empirical evidence on the girl-child situation in Nigeria in particular and very limited studies highlighting the cultural insights into some of the problems confronting her. Hence, this study shall adopt a holistic approach in order to explore the socio-cultural factors and practices affecting the girl-child among the Annang people of Akwa-Ibom State, Nigeria. Indeed, it is a holistic way of focusing on a multi-causal investigation of behaviour of parents at the household level and significant others towards the girl-child in a cultural-specific context, with specific reference to the cultural norms, values and practices of the Annang people. On the other hand, household discriminatory practices refers to denial of equity to the girl-child in the distribution of resources, assignment of domestic work, access to education and family allocation of food at the household levels vis-a-vis the boy-child.

\subsection{Objectives of the Study}

The broad objective of the study is to investigate the socio-cultural factors and practices affecting the girl-child among the Annang people of Akwa-Ibom State. The specific objectives are to:

1. Examine the socio-cultural factors that engender household discriminatory practices against the girl-child;

2. Investigate the nature of the household discriminatory practices that affects the well-being of the girl-child among the Annang people of Akwa-Ibom State.

3. Explore the perception of the girl-child herself towards household discriminatory practices.

\subsection{Literature Review: The Concept of the Girl Child}

The girl-child is a biological female offspring from birth to eighteen (18) years of age. This is the age before one becomes a young adult. This period covers the crèche, nursery or early childhood ( 0 to 5 years), primary (6 to 12 years) and secondary school (12 to 18 years). During this period, the young child is totally under the care of the adults who may be her parents or guardians and older siblings. It is made up of infancy, childhood, early and late adolescence stages of development. During this period, the girl-child is malleable, builds and develops her personality and character. She is very dependent on the significant others, those on whom she models her behaviour, through observation, repetition and imitation. Her physical, mental, social, spiritual and emotional developments starts and progresses to the peak at the young adult stage (Fisho-Orideji, 2001; Kapur, 2005; Offorma, 2009).

For a girl child to become a proper and useful adult, she needs both informal and qualitative formal educations. These will enable her to develop her mind, intellects and skills to be able to contribute meaningfully to her society. 


\subsection{Culture}

Culture is the characteristics of a particular group of people defined by everything from language, religion, cuisine, social habits music and arts. According to E.B Tylor, it is that complex whole which includes knowledge, beliefs, arts, morals, law, custom and other capabilities acquired by man as a member of the society. It is the shared pattern of behaviours and interactions, cognitive constructs and effective understanding that are learned through a process of socialization. These shared patterns identify the members of a culture group while also distinguishing those of another group. It is a people's way of life i.e. the fundamental ways of doing things common to a people.

\subsection{Household Discriminatory Practices against the Girl-child}

The growing interest in human rights especially as it is affected by cultural or customary practices in relation to the rights of girl-child in different communities in Nigeria has no doubt increased. Its prevalence has necessitated human rights activists/groups to discuss at different instances why, cultural practices are often cited as justification for denying girl-child a wide range of basic rights and the seeming way forward. Girl-child all over the world suffers from and is faced with many, peculiar and complex problems. Many of these problems revolve around their rights within different societies. This situation is largely as a result of and exacerbated by, the existence of several discriminatory practices against them. These problems manifest in very different forms in various societies with extensive implications and it is very prevalent in the Nigerian society. The problem arose as result of various factors which include economic, social and cultural. It is accompanied by adverse consequences to the woman, family and society.

Nigeria as a country is made up of people from different ethnic groups and cultural practices with the dominant groups being the Igbos, Hausas and Yorubas. Some of the cultural practices have contributed to the abuse of the girl-child and these discriminatory practices embarked upon by the male dominated society in Nigeria, thus come to mind.

According to Igube, (2004), cultural discrimination against girl-child merely on the ground of their sex has also constituted a grave impediment to the women's right as first and foremost a human being that breathes the same air as men and has the ability to think and do things as any man. Girl-child is looked upon in many traditional societies as weak persons who must be protected at all times and as persons who cannot fend for themselves, without the guidance of men. They are often not allowed into the presence of men especially when crucial family or community issues are being discussed. Labour or tasks are usually shared according to sex. Thus, there are certain tasks reserved for men and the girl-child dares not engage in them, (Igbolo, 2011). These perceptions of girl-child by men have made the average woman particularly in many cultural settings in Nigeria to look upon men as lords and have caused them to develop inferiority complex to their detriment.

It is important to note that since the attainment of Nigeria's independence, little or no attention has been paid as regarding "girl-child" in the laws so far made. The Constitution of Nigeria (1999, as amended, 2011) and the previous constitutions of Nigeria merely make general reference to the people of Nigeria as citizens without singling out the "girl-child". The only provision that recognizes girl-child is the reference to the citizenship of foreigners married to Nigerians. The Criminal Code of the Federation of Nigeria is one of the very few laws that recognize the need to specifically protect girl-child's rights as it contains provisions relating to infanticide, indecent assaults on girl-child, brothels, prostitution and unnatural offences. It appears, therefore, that girl-child are not given adequate protection by Nigerian laws, as the protection available remain minimal compared to those in developed and advanced nations.

It should, however, be noted that Nigeria is a signatory to many international, regional and sub-regional human rights instruments and has ratified some of these instruments that protect and guarantee the rights of the girl-child; amongst which are conventions touching on the rights of girl-child and the child. For example, there is the Convention on the Elimination of all Forms of Discrimination against Women (CEDAW, 1979), ratified by Nigeria in December 1991. The Universal Declaration of Human Rights (UDHR) adopted in 1948, the African Charter on Human and Peoples Rights in 1986, ratified and domesticated by Nigeria and the Convention on the Rights of the Child adopted in 1989 and ratified by Nigeria in 1992 and most importantly the Protocol to the African Charter on the Rights of Girl-child in Africa, 2003 - a unique piece of legislation which takes into consideration the provisions of other international instruments on human rights that touch on girl-child's rights and the need for equality and freedom from discrimination. It also takes into consideration the peculiar circumstances of girl-child in Africa and their vital role in development. The protocol certainly could have been the key to a new dawn for Nigerian girl-child, but the sad thing is that the reality seems a far cry away.

This protocol was adopted on 11 July 2003 by the AU to strengthen the promotion and protection of girl-child's rights. The preamble highlights several considerations necessitating the protocol. These considerations include the recognition of Article 2 of the African Charter on Human and Peoples' Rights, which enshrines the principle of non-discrimination. It also includes Article 18, which calls on all states to eliminate discrimination against girl-child. It also includes provisions which recognise girl-child's essential role in development, the principle of promoting gender equality as enshrined in the Consultative Act of the AU as well as the New Partnership for Africa's Development (NEPAD). 
By virtue of these protocols, Nigerian girl-child is supposedly guaranteed the right to dignity; the right to life, integrity and security of person; freedom from harmful practices which negatively affect the human rights of the girl-child; equal rights in marriage; equal rights in cases of separation, divorce and annulment; the right to equal protection and benefit of the law; the right to participate in political and decision making process; the right to a peaceful existence and participation in the promotion and maintenance of peace; the right to education and training; equal opportunity in work and career advancement; the right to health, including sexual and reproductive rights; the right to food security; the right to adequate housing; the right to a positive cultural context; the right to a healthy and sustainable environment; the right to sustainable development; widow's rights; the right to equitable share in inheritance; the right of the girl-child to special protection and freedom from violence; the right of the girl-child with disabilities to special protection and freedom from violence; the right of the girl-child in distress to special protection; and the right of remedy to any woman whose right or freedom has been violated.

Despite the provisions of the protocol recognising and guaranteeing rights and the obligation of the Nigerian government, lives of Nigerian girl-child are yet to attain a commensurate level of improvement. The Girl-child ranks lower than men in all indices of development in the country as girl-child's well-being are rather faring worse. In most cases, legislation are yet to be promulgated and schemes put in place to enhance girl-child rights and equal opportunities, even if it means the entrenchment of an affirmative action. The rich provisions of the protocol recognising and guaranteeing girl-child's human rights in Nigeria promise a beautiful future for girl-child, if the government fulfils its obligations.

The most affected rights of the girl-child are their rights to human dignity, life and personal liberty. Human rights education will go a long way in sensitising the girl-child to be knowledgeable of their predicament. Reorientation will make men appreciate that a situation where utilization of abundant energies are untapped because of cultural practices whose values are doubtful does not mean well for our collective emancipation from old customs.

\subsection{Implications of Discriminatory Practices on the Well-being of Girl-child}

The issue of discrimination against the girl-child has remained an unresolved issue in the society and a major concern in academic discourse. In every civilized society and especially in the African context, children are regarded as the pride of the parents and the greatest value the society possesses. This is why children are mostly cherished and consciously protected from all forms of hazards and abuse. However, girl-children have not been so lucky to be cherished, protected and loved in our society due to certain traditional practices, stereotyping, cultural and religious beliefs which put them at the risk of abuse and neglect (Alabi, Bahal \& Alabi, 2014).

A lot has been done in the area of documentation and assessment of the situation of the girl-child vis-à-vis the male-child. Available data have shown the detailed situation reports of the girl-child from birth. Some researchers have documented the general inferior economic, social and political status of the girl-child while recent studies are also showing the state of her existence from the formative-infancy stage through youth to the adult stage (Igube 2004; Offorma 2009). The girl-child problem around the world has many dimensions but the root of all kinds of discriminations and bias against the girl child lies in the customs, traditions and typical mindset of the society which considers the girl child and girl-child as inferior beings. Girl-child and girls have been treated in the most inhuman ways from the inception of human civilisation (Igube 2004). The legacy of injustice against the girl child has continued in some parts of the world especially in African and Asian countries. Female feticide, female infanticide, sexual abuse, marginalization in terms of nutrition, health care and education, violence against girl-child and bias against girl-child in all spheres of life including social, political, economic and religious spheres is a common norms in today's world. Generally, girls as well as girl-child do not have decision making power of their own; it is always somebody else who makes decisions for them. An adolescent girl is married without her consent and becomes pregnant long before her body and emotional/psychological feelings are mature or ready for it. Half of the total sexual assaults in the world are committed against girl children (Alabi \& Alabi 2012). One of the leading causes of death among girl children is the complications from pregnancy and child bearing (Fisho-Orideji 2001). This paper therefore, examined the general problem facing girl-children and the implications on the education opportunities available to them.

Decision making both in the home and in governmental affairs has always been

viewed as the exclusive preserve of men. This has been strengthened by various societal policies many of which found solace in the biblical injunction instructing women to remain subordinated to their husbands. Stereotypic beliefs about women as the weaker sex with an inconsequential contribution to development, if any, has further clamped down on the productive activities of women. They are thus; not favoured on many policies relating to socio-economic and political issues for which men are believed to be key role players and indeed the real policy makers. Even where such policies remains silence on the degree of involvement of both sexes, the institution of the family rather assumes the little or no participation of the female gender thus subjecting them to spectator's activities. Two areas where this appears glaringly visible are in education and political affairs. 
Most traditional African societies hardly see any reason why the girl child should acquire western education. They are mostly considered as part of their husband's assets, and as such money should not be wasted on them. They are however socialized the African way to be passive, caring, submissive and highly active at domesticated jobs. Their male counterparts were also taught to be active, strong-willed, athletic, risk-takers, and engaged in other activities depicting manhood. All of these were reinforced by the rich African folklores, riddles, literatures and cultural activities.

Female enrolment into schools at all levels has never matched that of their male counterparts. For instance, in 1995, female enrolment in primary schools was recorded as $47.8 \%$ while that of male was put at $52.2 \%$ (NEEDS bulletin 2006). A decrease was shockingly observed in female enrolment in 1999 with $45.9 \%$, revealing a $1.9 \%$ decrease. At the same time, male enrolment shot up by $2 \%$ in1999 over that of the 1995 data with $54.1 \%$ (NEEDS bulletin 2006)

The above, no doubt is bound to have a corresponding effect on female employment in the country, as well as their participation in decision-making. For instance, Igube (2004) recorded women participation at world level at $11.4 \%$ while in Nigeria, the Independent National Electoral Commission. (INEC) report shows that only about $10 \%$ and $15 \%$ women contested both the presidency and vice presidency seats in 2003 and that $13.6 \%$ of ministerial seats were granted women while $27 \%$ were appointed permanent secretaries (inecnigeria. org).

While this is a remarkable achievement over those of past years, it is still believed to have fallen short of expectation. This was held on to by some upper class women who erroneously believed that women population in comparison to that of men should be the sole criterion for appointments into positions, jettisoning professionalism and the actual female population in such establishments, While this argument may appear plausible anyway, it should also be pointed out that the damage caused women by our age-long archaic tradition and customs cannot be overcome overnight by appointment of women into public offices whether or not they possess the requisites for such, for now. This however is not to intending a campaign of the traditional conception of housewifery for women but a gradual process of transformation of the female species in developmental activities.

Cultural practices across societies no doubt have further relegated the womenfolk in societal activities. This is seen in the non-recognition of women as of any greater economic value other than reproducers, baby producers and home managers. This is in spite of the fact that almost half of the world population were women (UN,2000), majority of whom $(80 \%)$ were producers of foods sustaining even the men in some countries, even though they only have access to about $1 \%$ of world land (Offorma, 2008, UN,2000).

Following the socialization of both sexes, boys were meant to follow such adventurous paths while girls were made to play second fiddle roles. This explains while such jobs as engineering and medicine were regarded as male profession while secretarial studies, and nursing were believed to have been specially designed for female, This fact was corroborated by the United Nations (1985) report that women filled about one-third1/3\%) of the labour force but performing menial jobs which attract low wages, compared to men.

It must however be noted that the traditional African societies accorded women their respects and distinguish place in the society. Women play vital role in the religious institutions to the extent that they have the final say on some occasions. Notable among some of those exalted positions are the 'Yeye Osun, the godess of the Osun river in one of the Nigerian states which host millions of tourists yearly, the "eyesoun (kings wife) and the 'Erelu', who is a respectable decision maker in the 'Ogboni' secret society. The aforementioned has made many of our traditional women accepted the derigeur even to the extent of christening other women deviants campaigning against inequality of the sexes. Some of such name tags include 'Egbe ki loko o se (women who disregard their husbands). 'Oko kan o ka'gbon or lya ndagbe Baba nyowa and Dalemosu (meaning; divorcee or independent or free lance, prostitute or worst still immoral women).

The above, found solace in religious leaders and other women as very many of these women liberation fighters are either divorces, widows or separated from their husbands. Given the above, one would be less surprised knowing that women agitations were not given its deserved attention from the very beginning of their agitation. It was the regime of General Babangida that pushed the agitation higher with the establishment of the better life for Rural women by the then first lady; Mrs Mariam Babangida' Apparently she was the first to be addressed officially as the first lady, while the husband was equally the first ever - known 'military - president' in the country. The corruption and deceit that became the characteristic feature of this administration could not allow many to believe in the mission of the first lady.

The global attention being given to women is a product of many years of agitation by women activists, who inspite of all odds protested the discrimination as well as the violence being faced by women. These groups of women brought to the fore the second fiddle position of women in America as a form of discrimination and indeed deprivation. The convention of 1848 was aimed at addressing this and it recorded a little achievement of sensitizing government about the plight of women. This led to the establishment of the Women International Organization by the League of Nations in 1919 (Aina \& Abdullahi, 2004). 
At the inception of the United Nation organization in 1945, the organization was taken over with more attention given to it. The UNO economic survey revealed women as being terribly affected by the world poverty level. This led to the declaration in 1948 of the Universal right of women (Lundberg, 2005). Following this was the 1975 women conference in Mexico which brought about among others, the institutionalization of an action plan for women (Punalekar, 1995) with a major aim of reviewing the multiple roles of the female gender in the society. A major landmark of the conference is the declaration of the period between 1975-1985 as the decade for women.

The Copenhagen conference of 1980 which was intended to speed action on the

major issues raised at Mexico also recorded success by sensitizing government on the need to enact laws to protect the right of women as well as conduct research on the significant role of women, their labour force participation, their needs and the eradication of barriers against women as it relates to education and training, employment, and dad decision making (Punalekar, 2004).

The above was also improved upon at the 1985 Nairobi conference. Here emphasis was on how to improve women status by financing education to eradicate poverty of women and combating poverty to ensure equitable balance between both sexes (Pradhan, 2001). The Beijing conference of 1995 was no doubt the most remarkable of all the world conferences on women. Most countries including the third world countries attended and certain critical areas such as health and harmful practices against women, education, conflict, the issue of the girl-child, poverty and decision making were majorly addressed. The major concerns were about womens' involvement in decision making at all levels as it is believed that, it is a major instrument of change. This was further buttressed by CEDPA (1997) and USAID (2002) that "access to power would make women have a fair share of state's resources and would also conscientize them of their rights". Anyanwu, (1995) had earlier maintained a similar opinion that 'politics' is all about who participates in decision making..... If this assertion is true, then, one would not be surprise at the stand of women to be more active politically. It was this situation that sparked off series of political activities of women across the globe. Nigerian women got reawakened especially after the Beijing conference. They have been more visible on the political terrain than before. According to Igube, (2004), there appears a slight improvement in the political participation of women in 2003 compared to other past years. Both the 2007 and 2011 elections equally show greater improvement over that of 2003. For the first time, Nigeria recorded the first female speaker of the second legislative house in 2007. All these were made possible by the concerted efforts of the government to raise the political awareness of women through; the establishment of the national policy on women with the intention of increasing women participation to $30 \%$ in both the legislature and executive and secondly through the establishment by the Federal Ministry of Women and Youth Development (PMWAYD), of an action committee to mobilize women for the purpose of election. Aside from the above, the launching of 'Women money for women election' by some non-governmental organizations was meant to help women aspirants achieve their targeted objectives.

\subsection{Theoretical Framework}

The theoretical framework adopted offers insights on the mechanism and context underlying the perpetuation of the household discriminatory practices at the household levels. With regard to the theoretical framework, Weber's social action theory, the sex-role theory and the feminist theory on patriarchy were employed to provide a nuanced understanding of the factors that engender household discriminatory practices. Weber's social action theory posits that individuals attached subjective meanings to their actions and social actions which are intentional behaviour of actors involving motives and feelings (Ritzer \& Goodman, 2003). An action is regarded as social insofar as its' subjective meaning takes account of the behaviour of others, whereby the acting individual saturates the social context with meanings. In addition, social action or human behaviour displays certain "relations and regularities" which can only be understood when juxtaposed with the cultural significance attached to them by the acting individual ( Ritzer and Goodman, (2003) note that one of Weber's most critical methodological concepts is "verstehen". It implies that a sociologist should attempt an interpretative understanding of any given social action in order to tease out the causal explanation with regard to its cause and effects. Furthermore, social scientists in their effort to seek for plausible explanations should take into account the actors' emotions, thoughts, beliefs and attitudes. However, Weber's social action theory may not have fully explained the mechanisms that perpetuates and sustains household discriminatory practices against the girl-child. The feminist theory on patriarchy as well as the sex role theory fills the gap and limitations in this regard.

Patriarchy within feminist scholarship, with specific reference to theory and practice, has been examined differently from the liberal to socialist feminism (Ritzer and Goodman, 2003; Randall, 2010). In contemporary times in feminist scholarship, it has been used to analyse the principles underlying women's domination and by extension the girl-child. It refers to the totality of structures of domination and exploitation that affects women's position and by extension, the girl-child's position in society. Also, it represents the institutionalisation of men's power over women in both the public and domestic spheres; household, polity, economy and heterosexual relations (Coetzee, 2001; Giddens et al., 2005). At 
the household level, it is a system of hierarchical and unequal power relations whereby, the father as the head of the family controls all the economic resources, takes all the major decisions of the family and thereby maintained an ongoing control over all members of the family and those related to it (Alcoff, 1990).These hierarchical and unequal power relations are legitimised through ideologies, social practices and other institutions such as religion, kinship and family system, media, law and even the state. Also, at the household level, family patriarchal values as well as masculinity and femininity character stereotypes are reinforced through the process of gender socialization (Alcoff, 1990; Coetzee, 2001). Mc Fadden, (1994) cited in Kameri-Mbote, (2005) notes that:

Patriarchy is the framework within which gendered relations of power are played out and has assumed a dominant role and relationship vis-à-vis other forms of social organisation to the extent where matrilineal forms of social processes survive, it is the patriarchal power relations which underpin and strongly influence the manner in which men and women live together in such societies.

Patriarchy is the root cause of household discriminatory practices against the girl-child. At the household level, unequal power relations placed women and girl-children at a disadvantaged position. Consequently, a process of subjugation of girl-children and the privileging of men and boy-children as heads of the household is often the case in most families and communities that are patriarchal in nature.

Sex-role theory posits that individuals occupy different sets of roles which are socially determined. Individual actors carried out their specific roles guided by the prevailing social norms and values. There are marked differences by gender. Men, women, girls and boys are ascribed different roles. (Bradley and Moore, 1996; Schaefer, 2008).Also the individual's actions, behaviour, dispositions and desires are usually determined by the set of roles occupied by each actor. The differing roles occupied by individual actors are presumed to create gender stereotypes, on feminity and masculinity which accounts for differences in behaviour. Men and women are "systematically funnelled into social positions that attracts greater amounts of value (tangible and intangible) to men than women" (Scanzoni and Szinovacz, 1984). This layering-effect invariably implies that women and girl-children inclusive occupy subordinate positions. The set of roles has ascribed social status, whereby women's role are linked to the "domestic domain" and occupy a lower status and men who occupy roles associated with the "public sphere" are accorded higher status. Society ensures conformity to role performance through a set of rewards and punishments. Society ascribes roles and defines associated dispositions, behaviour patterns for each individual actor which the individual internalizes during socialization. Parents ensure that the girl-child internalizes the ideal notion of femininity. Such as learning to be submissive, caring and acquiring skills associated with her future role as a wife and mother. As a result of the strict division of labour the girl-child is limited to roles that are limited to domestic domain.

A triangulation of Weber's social action theory, the feminist theory on patriarchy and the sex role theory provided a comprehensive framework that highlighted the links between the variables being investigated. The social action theory of Weber was employed to describe the motives of individual actors towards the girl-child. It posits that household discriminatory practices towards the girl-child are engendered by motives that are situated within a given social context and individual actors attach cultural significance to their actions towards the girl-child. Also, it suggests that these practices are intentional actions of individual actors at the household level which involves rationalization of the value of the girl-child vis-à-vis the boy-child. On the other hand, the feminist theory on patriarchy seeks for casual explanation on the perpetuation of the girl-child phenomenon. Traditionally, the Annang society is seen as a patriarchal society, the kinship systems are largely based on patrilineal descent. The kinship system is the foundation of a pervasive patriarchal ideology that leads to the rationalization of differential access of men and boy-children; women and girl-children to the material and symbolic resources of the society. Finally, the sex-role theory adds another dimension to the analysis of the girl-child phenomenon. It opines that roles and social status are socially determined and each individual acquires the character of either femininity or masculinity through gender socialization. Therefore, the attitude and actions of individual actors towards the girl-child is based on societal conception of masculinity and femininity. Also, gender stereotypes are also associated with the girl-child phenomenon.

\section{Methodology}

Isiugo-Abanihe (2002) posited that descriptive studies are specifically designed to depict precisely the attributes of a particular situation, community or group. As was the case with this study, the multi-methodological descriptive approach was adopted to explore the socio-cultural context of the girl-child phenomenon among Annang people. The study included both quantitative and qualitative research designs in order to fulfil the objectives of the study. The quantitative method involved the use of a structured questionnaire while the qualitative methods made use of In-Depth Interviews and FGDs. Thus, for the purpose of this study, the descriptive Survey research method was adopted. The research design for this study is deemed appropriate, because of the numerous constraints usually associated with the enumeration of a large population. According to Rowe, (2005), survey research studies both large and small population by 
selecting and studying samples chosen from the populations to discover the relative incidence, distribution, and interrelations of sociological and psychological variables. In view of this assertion, the survey research would enable the researcher to draw from population sample that would be representative of the entire population and provide a basis for generalization.

\subsection{The Population of Study}

The Annang (also spelled Anaang) is a cultural and ethnic group that lives in South-South Nigeria. At present, the Annangs have eight local government areas of the present thirty-one local government areas in Akwa Ibom State of Nigeria (Akwa Ibom State Local Government Areas), namely Abak, Essien Udim, Etim Ekpo, Ika, Ikot Ekpene, Obot Akara, Oruk Anam and Ukanafun in Akwa Ibom State of Nigeria. They were formerly located in the former Abak and Ikot Ekpene Divisions of the Annang Province, in the former Eastern Region of Nigeria.

The Annang people speak a language called Anaang. They pride themselves in the ability of eloquent speech and refer to a good speaker as "Akwo Annang (Umoh, 2004). The Annang are known for their carved masks with grotesque features, known as idiok, which are considered dangerous and may only be viewed by members of the ekpo cult.

The Annang people of South South- Nigeria consist of over one million people in the western part of Akwa Ibom State of Nigeria. They share a common boundary with the Igbos to the northwest and southwest, the Ibibios to the northeast, east, and southeast. They speak Annang language with its various dialects. The culture and traditions of the Annangs requires great respect for the elders. This allows the chiefs and elders to govern effectively. It is the elder from each family that sits in the village council where decisions are made in a republican fashion. The Annangs are farmers, artisans, and traders. Their craftsmanship in raffia and woodcarving is well known. Their trading in palm oil led to the establishment of the United African Company (UAC) in Ika. This was the site in 1929 where the now famous Aba women's riot started.

Annang society is patriarchal. Individuals locate their place in the social world from the Idip, literally translated as "womb". Thus a brother/sister from the same Idip means that they can trace their origin to the same mother or father. Since polygamy is practised in the society, those who can so trace their ancestry to the same parents form Ufok (literally a house or compound). Several ufoks make up Ekpuks or extended family and several Ekpuks (extended families) make up "Idung" (meaning village) and several villages make up the "abie" or clan (Udondata \& Idem-Agozino, 2001).

Leadership at the family, lineage, village, or clan level remains the prerogative of the men, and lineage ties extends to women even after marriage. There are many societies and associations (Urim) for men and women which are very important in traditional village life. Individuals are measured by both the number and types of memberships in Urim and by the achievements of one or more Urims (Udo, 1983). Governance is done by elderly males who act as the legislative arm called Afe Isong, directed by the Obong or Abong Ichong (Village Chief and Clan Chief) who is the head and the chief executive but without the authority beyond what the Afe Ichong gives. A chief can be appointed by the Afe or can be an inherited office.

\subsection{Sampling Procedures}

This study adopted a unique methodological approach in the selection of the sample population. The sampled population comprised of girl and boy-children between 10-17years. The study population is a pair of adult women and the girl-children (daughters) of the specified age were randomly selected from the households. Also, adult men and their boy-children (sons) were randomly selected from a different household. The rationale for the adoption of the study population is to achieve a comparison among the sub-groups.

A multi-stage sampling technique was adopted for the study. Firstly, Abak Local Government Area was purposively sampled in view of the fact that Abak is one of the former Annang provinces where Annang are predominantly located. Secondly, 5 political wards out of a total of 13 listed wards, in the selected Abak Local Government Area were purposely selected. Thirdly, a complete list of the enumeration areas (EAs) demarcated for the 2006 Census by the National Population Commission were obtained. There were a total of 60 EAs out of which 3 EAs were randomly selected and this represented 1.0 percent of the total EAs of the selected LGA for the study. Fourthly, 3 EAs were further sub-divided into clusters ranging from an average of 2-7 clusters. Consequently, a total of 125 Households (HHs) were randomly selected from the selected LGA.

\subsubsection{Research Design}

The study adopted the triangulation approach in research design and data collection techniques. These comprised of both quantitative and qualitative methods. Exploring the socio-cultural milieu of household discriminatory practices towards the girl-child required the adoption of such methods in order to provide an in-depth understanding of the girl-child phenomenon among the Annang.

In view of the target population adopted for this study, questionnaires were designed for girl-and boy-children. Both 
questionnaires elicited information on various aspects as identified in the objectives of the study. The questionnaire comprised of structured questions with pre-code responses as well as few open-ended questions. In some cases, the interviews were conducted in Annang language.

Fourteen In-depth Interviews (IDIs) and FGDs were conducted as part of the study, involving the following sub-groups: traditional rulers and title holders (4), religious leaders (3), male (4) and (3) women community leaders. The in-depth interviews focused on those socio-cultural factors associated with the girl-child phenomenon, the traditional practices (child betrothal, restrictive food taboos and bodily beautification marks) on the girl-child vis-à-vis the boy-child. The in-depth interviews and FGDs related the past with the future in order to capture the dynamism of the society with respect to the girl-child phenomenon.

The IDIs and FGDs were recorded on a tape-recorder and were transcribed. Guided by the research questions, key issues and concepts raised in the study, the transcribed data were coded into various categories and themes with value labels. Furthermore, patterns and explanations were drawn through constant comparative methods, concept mapping of the transcribed data (Babbie, 2007). Quantitative data entry was carried out using the Statistical Package for the Social Sciences (SPSS) version 17.0. Data analysis involved the use of frequencies and percentages to identify the factors that engendered discriminatory behaviour towards the girl-child.

\section{Results}

This section deals with the presentation and discussion of results obtain during the course of data collection. Thus, the tables presented contain a summary of numbers and valid percents of participant's views and opinions.

The data on table 1(see appendix) shows the frequency distribution of sex of respondents, it revealed that $98(82.4 \%)$ of the respondents were females, while $21(17.4 \%)$ were males. This means that substantial majority of the respondents were female. Which goes to contradict Aderinto's (2005) study which revealed that men participate more in voluntary responsibility than their female counterpart?

Also, the age frequency (see appendix) of the respondents' reveals that $2(1.7 \%)$ of the respondents are in the age category of $16-20 ; 19(16.0 \%)$ of the respondents are within the ages of $21-25$ years, $39(32.8 \%)$ of the respondents are within the age of 26-30 years; while 43 (36.1\%) of the respondents are within the age range of 31-35 years. It is therefore obvious that majority of the selected respondents are within the age range of 26-35. This therefore guarantees the authenticity of whatever information elicited from the respondents on the issue under investigation given the fact that with that age bracket, maturity plays a key role.

Again the frequency distribution of the respondents educational attainment (see appendix) shows that $11(9.2 \%)$ of the respondents have primary education, $59(49.6 \%)$ of the respondents had secondary education; while $17(14.3 \%)$ of the respondents had tertiary education, $3(2.5 \%)$ of the respondents had koranic education and $29(24.4 \%)$ of the respondents have never attended school. From the table it is obvious that majority of the respondents had secondary education.

The frequency distribution of respondents' marital status (see appendix) revealed that 97 (81.5\%) of the respondents are single, while $20(15.4 \%)$ of the respondents are married; while $2(3.0 \%)$ of the respondents have divorced/separated. It is therefore clear that majority of the respondents were single.

Table 1. Respondents view on reasons why Girl children are on the street

\begin{tabular}{llll}
\hline Reason & Frequency & Percentage $\%$ \\
\cline { 1 - 2 } Conflict with parents & 5 & 4.0 \\
To help parents & 4 & 3.4 \\
Poverty & 110 & 93.3 \\
Total & 119 & 100.0 \\
\hline
\end{tabular}

Source: Field survey 2014

The table above shows the frequency distribution showing the reasons why children take to the streets. Five percent $(4.0 \%)$ of the respondents revealed that children are on the streets because they are in conflict with their parents; 4 $(3.4 \%)$ of the respondents work to help their parents while $110(93.3 \%)$ of the respondents revealed that children are on the streets because of the prevailing poverty situation in the country.

Evidence from the literature reviewed also attributed poverty as one of the major factors responsible for why Girl children are on the street. This agrees with Ogidi's (2000) claims that the high rate of street children in Nigeria is due to poverty worsened by chronic economic depression. Also ILO (2006) claimed that poor families rely upon children to 
improve their chances of attaining basic necessities of life. It also estimated that more than one fourth of the world's people live in extreme poverty.

Table 2. Percentage Distribution of Girls and Boys by their Ranked Position in the Family and Age

\begin{tabular}{lcll}
\hline Variable & Girl-Children & Boy-Children & All Respondents \\
\hline $\begin{array}{l}\text { Rank of Child by } \\
\text { Order }\end{array}$ & & & \\
$1^{\text {st }}$ & $27.3(43)$ & $36.6(41)$ & $31.8(54)$ \\
$2^{\text {nd }}$ & $18.4(15)$ & $16.6(24)$ & $17.5(14)$ \\
$3^{\text {rd }}$ & $22.2(24)$ & $19.0(17)$ & $20.7(35)$ \\
$4^{\text {th }}$ & $11.1(16)$ & $11.2(4)$ & $11.1(5)$ \\
$5^{+}$ & $20.0(35)$ & $16.6(24)$ & $18.9(15)$ \\
Total & 100.0 & 100.0 & 100.0 \\
\hline
\end{tabular}

Source: Field Survey, 2016

Table 2 indicates the specific socio-demographic characteristics of girl-and boy-children. Generally, 31.8 percent of the respondents are first-borns in their families. About 28.0 percent of girl-children were first-born, compared to over one-third of boy-children $(36.6 \%)$. Also, 22.2 percent of girl-children were ranked $3^{\text {rd }}$ in their families compared with 19.0 percent of boy-children in their respective families. The overall percentage distribution of girl and boy-children in the $3^{\text {rd }}$ rank position was 20.7 percent. About 17.0 percent of boy-children were ranked $2^{\text {nd }}$ and $5^{\text {th }}$ and above respectively. More girl-children were ranked $2^{\text {nd }}, 5^{\text {th }}$ and above relative to boy-children. Table 2 indicates that 22.9 percent of girl-children were aged 10 compared to 18.2 percent of boy-children. More boy-children $(24.7 \%)$ were aged 17 as compared to girl-children in similar age group (17.4\%). The mean age for girl-children was 13 years compared to 14 years for boy-children. The overall mean age was 13.5 years and the median age for all respondents was 13 years.

Moreover, schooling status of respondents indicated that more girl-children were out of school than boy-children. About 67.0 percent of boy-children were in-school as compared to 44percent of girl-children. This result revealed a preference for boy's education than girl's education. This goes to corroborate the findings of Ogidi, (1997); Indabawa, (2004). With regard to their level of schooling, more than half (53.1 percent) were attending primary school as at the time of the survey. This signified that girl-children faced discriminatory practices with respect to access to education. When parents had to make a choice on who should have access to education, boy-children were more favoured than girl-children. The status of girl-children would continue to be low, unless the issue of unequal access to education is addressed.

\subsection{The Definitive Features of Girlhood}

Table 3. Percentage Distribution of Respondents by their Conception of the Definitive Features of Girlhood

\begin{tabular}{llllll}
\hline Variable & Men & Boys & Women & Girl & All Respondents \\
$\begin{array}{l}\text { Physiological features } \\
\text { define girlhood }\end{array}$ & $48.7(46)$ & $47.7(45)$ & $9.0(13)$ & $9.5(11)$ & 99.2 \\
$\begin{array}{l}\text { Good skills in housework is } \\
\text { a mark of girlhood }\end{array}$ & $52.3(54)$ & $53.3(55)$ & $98.3(67)$ & $91.5(79)$ & 97.1 \\
\hline
\end{tabular}

Source: Field Survey, 2016

Table 3 shows the percentage distribution of respondents by their conception of the definitive features of girlhood. There was an overwhelming consensus among all of the sub-groups in the sample that girlhood was defined by physical and physiological feature of the "female" gender. In addition, the acquisition of good skills in housework was considered as the hallmark of girlhood. Corroborating these views, a girl-child FGD participant within the age bracket 10-17 years stated:

A girl is usually known by her physical features which are quite different from that of a boy. A girl would one day become a mother by giving birth to children; no boy could do that because God has not made it so.

An adult male FGD participant from aged 20-44years highlighted another aspect of the cultural construction of girlhood when he stated:

The foregoing cultural construction of girlhood by the respondents indicated that their conceptions were shaped by socio-cultural ideas on the notion of femininity as well as the biological classification of features of the female gender 
with respect to the physiological and the aesthetic presentation of girlhood. The body was central to gender identity constrution, it was seen as a type of cultural text whereby the girl-child usually expressed her identity. Thus, sociocultural ideas about the notions of "femininity" and "masculinity" take tangible form on the physical locale of the body (Bordo, 1993; Offorma, 2008).

\subsection{The Prescribed Roles of the Girl-child}

An overwhelming majority of the respondents in the sample supported five prescribed roles of the girl-child, namely:

- $\quad$ To undertake all domestic work

- Acquire skills in buying and selling

- Assist mother in her trade

- Care for young ones

- $\quad$ Expected to assume the role of wife and mother

The prescribed roles of the girl-child identified by the respondents conform to the traditionally ascribed roles of the female gender which were mainly in the "domestic domain". The cultural construction of girlhood provided insights on the societal representation of her roles and responsibilities that would later transform her into a woman. Offorma, (2009) stated that the categorization of bodies as either "female" or "male" transmitted "culturally symbolic gendered meanings that translate into social expectations for behaviours and social roles in the material world". In sum, the girl-child's experience of household discriminatory practices is closely linked to the socio-cultural construction of girlhood, which could not be divorced from the material and structural systems that shape her daily life. Also, socio-cultural ideas, gender stereotypes about femininity also shaped their conception of the prescribed roles of the girl-child, her value and character index.

\subsection{The Perceived Appropriate Qualities of the Girl-child}

Five specific qualities were identified as the most important appropriate qualities for a girl-child to possess. The following are put in descending order: patience (96.4\%), kindness (94.2), and good skills in domestic work (88.2\%), obedience $(87.4 \%)$ and respect for elders $(57.6 \%)$. The sum of these qualities was closely associated with social expectations on the notions of femininity in respect to her future as a wife and mother. In sum, the qualities or virtues identified by the respondents could be classified as "feminine qualities' which clearly defined girlhood/womanhood.

Re-affirming this position one of the male FGD participants in age-group 45 and above noted:

Men and boys are the foundation of every community. The male child is seen as the owner of the household. He represents the family in the absence of his father in the community and inheritance of land, farm lands, properties and offices were for the male child and not the female. The boy-child has been given more honour and privileges, because he is seen as a "male" whom authority has been given to by the society.

An educated older female FGD participant within the same age group empathically supported and corroborated the position of the older illiterate male in this manner:

In our tradition, you do not even contest it. The boy-child, like his father has a higher status over and above the girl-child. We honour them; they are served food before any other person in the family. A girl is seen as a stranger who would eventually leave and the boy-child would be left to take charge of the household.

This implied that the boy-child was highly valued and ascribed a higher status than the girl-child. All the reasons proffered to justify the privileged and dominant position and status of the boy-child was a reflection of the patriarchal nature of the Annang. Like in most patrilineal societies the role of the male child cannot be overemphasized. The boy-child was seen as the representative of the family in the community and inheritance of land, farm lands, properties and political offices were through the male child as identified by the FGD participants. Bordo (2008) referred to it as the "vertical function" of the kinship system. 


\subsection{Socio-cultural Factors Associated with Household Discriminatory Practices}

Table 4. Percentage Distribution of Respondents by their Decision Making Pattern on Critical Household Issues

\begin{tabular}{lccc}
\hline Variable & Men & Women & Overall \\
\hline Who decides on major issues? & & & \\
Husband & $81.6(82)$ & $84.5(89)$ & 83.1 \\
Wife & $0.3(1)$ & $2.2(4)$ & 1.3 \\
Jointly & $18.2(27)$ & $13.3(5)$ & 15.6 \\
Total & 100.0 & 100.0 & 100.0 \\
\hline
\end{tabular}

Source: Field Survey, 2016

Table 4 shows the distribution of adult respondents by their decision making pattern on critical issues. About 83.1 percent of adult respondents opined that the husband decided on major issues. Decision making at the household levels was defined by societal expectations. Husbands played very key roles on critical issues that affect the well-being of the household such as providing household needs, which child should be sent to school and under what conditions.

Lending support to the findings of the quantitative data, an older non-literate rural male FGD participant from age sub-group 45 + years stated:

Men as heads of the family take most of the decisions even in small and big matters. The wife is expected to support and carry out those decisions without questioning the authority of her husband.

Similarly, an older non-literate rural female FGD participant noted.

If a husband decides that he would not send his female children to school because he feels that it would corrupt them, what can the wife do? She would not be able to force him to change his mind. He is expected to know what is best for his family.

In sum, decision-making at the household level can negatively impact on the aspirations of the girl-child particularly when parents did not value western education or when women were not involved in the decision-making process at the household level.

\subsection{Gender Stereotyping}

Gender stereotyping largely influenced the mindsets and individual actions of the respondents towards exhibiting intra-household discriminatory practices towards the girl-child. A number of gender stereotypes with respect to the notions of femininity, prescribed roles of the girl-child, valuation of the girl-child among some of the sub-groups of the sample were identified as follows:

"A man with only female children has no say in the community".

"Boys are more superior to girls".

"Domestic work is seen as girls' work".

These gender stereotypes influenced the actions of adult men and women towards their children. Corroborating these views, a male community influential noted:

The underlying motives that influence the actions of parents towards the girl-child are linked to deep-rooted beliefs, stereotypes about girls which may not necessarily be true. For instance, there is this belief that boys are more intelligent than girls as a result of this; some parents may not see the need to educate girls.

\subsection{Conception of Gender Roles}

Every community usually assigned distinct gender roles to its members. Similarly, among the Annang, distinct roles exist for each of the gender. There was a consensus among the various sub-groups on the specific roles assigned to girl-children. An urban in- school girl-child aged 12 years noted as stated below:

Girls usually cook meals, fetch water and firewood, clean the surroundings and also care for their younger ones.

An illiterate younger woman said:

When girls are about 5-6 or even 7 years, they can run errands, sweep the surroundings, wash plates, fetch water and even care for their younger ones also. Meanwhile, the older ones from 8 years and above wash plates, fetch water, fetch firewood, set fire, pound soup ingredients and also cook meals.

Indeed, the listed activities implied that roles assigned to girl-children were associated with the "domestic sphere" 
which had been closely linked to their future roles as "wives" and "mothers". Thus, the role assigned to each child was clearly distinct based on their gender. Consequently, parents assigned domestic chores to girl-children because traditionally it was seen as the prescribed role assigned to them by the community. On the other hand, boy-children were assigned roles that were in the "public domain", mainly masculine activities as exemplified by farming, hunting, building and other related activities. A religious cleric noted some significant issues on conception of gender roles as follows:

The male and the female have been made distinct by God and their roles are also quite different. When a girl is assigned domestic work or over-burdened with it, she is seen as performing her role as a girl and that of a mother and a wife in the nearest future. It is not seen as discrimination but a training ground for her future roles.

Another religious cleric stated his views in this manner:

In as much as God made the female and the male distinct with differing roles, nothing stops a boy-child from assisting to carry-out domestic chores when the need arises at the household level.

The dilemma of the girl-child phenomenon must had been that parents did not really view assigning domestic work to girls or her being over-burdened with domestic work, as "discriminatory". Rather it was seen as a required "training" that would assist her to assume her future roles effectively.

\subsection{Gender Socialization}

The girl-child was taught her ascribed roles and the necessary skills and values by her mother, other female members of her immediate and extended family kins and other women in the wider community. The girl-child was usually in the company of her mother and other female relations most times whether within the household or during market days. A woman interviewed revealed that:

When a girl-child is about age 4 the mother, other female relations and her elder sisters could send her to fetch water from the pot, carry plates or spoons during meal-time when the food is been served. She learns how to sweep the surroundings at least by age 6 , she can also be sent to pound soup ingredients at age 7 . Also, she could follow her elder sisters to the stream at age 7 and 8 years and remain in the kitchen area to run other errands. At that age, as well, she could be allowed to pound grains.

This implied that all she needed to learn about womanhood and motherhood emanated from the mother. Thus, when a girl-child was assigned any form of domestic chores, it was done within the context of her prescribed role and she was taught on how to carry out each of these activities. Besides, engaging in domestic chores was not seen as a "burden" but as part of "training" to fulfill her prescribed roles as a "mother" and "wife" in the near future. The exhibitions of household discriminatory practices against the girl-child were what had been internalized unconsciously during gender socialization by individual actors.

This is a clear indication that the notions about femininity shaped the cultural construction of girlhood. Consequently, the prescribed roles of the girl-child, her subordinate and secondary position accorded, as well as the gender stereotypes about the notions of femininity eventually influence individual actors' behaviour towards the girl-child. In a nutshell, the cultural construction of girlhood among the Annang was closely associated with her prescribed role in the community. Thus, a girl-child was assigned most of the domestic work at home and it was also seen as the work of girls rather than boys.

These affirmed the fact that the roles of the girl-child were within the "domestic domain" and within the household, where she was only to be "seen" not "heard". Her future role as a "wife" and "mother" limited her participation in communal activities that were male-dominated. At the household and community levels the girl-children were aware of the value and preferential treatment given to the boy-child. An in-school girl-child stated:

We are taught to show respect for the males in our families and our parents. From their day-to-day actions and activities we know that boys are more valued. They are given more respect and preferences in so many ways. A boy would follow the father for festivities or meetings in the community when they are of age. They ate different kinds of meats or fishes which girls are not allowed to eat because of our traditions... Boys are considered first with regard to schooling.

Consequently, the devaluing of the girl-child was due to her secondary and subordinate position vis-à-vis the position accorded the boy-child. Thus, intra household discriminatory practices against the girl-child were based on the value of her roles, worth and contributions to the household and its continuity as an entity within the community. These further underscored the patriarchal nature of the Annang society whereby male dominance permeated every aspect of societal life.

The girl-child faced household discriminatory practices at the household level because of her disadvantaged position 
vis-a-vis the boy-child. Educating a boy-child was seen as a priority; a girl-child would eventually bear the name of someone else and would eventually leave the household. Girls did most of the domestic work because a boy who was seen as a potential head of household should not be involved in girls' work.

\subsection{Perception of the Girl-Child towards the Household Discriminatory Practices.}

Table 5. Percentage Distribution of Girl-Children's Perception of their Disadvantaged Position

\begin{tabular}{lc}
\hline Variable & Girl-Children \\
\hline Parents are right for giving boys more privileges and preferences than girls & \\
Yes & $66.7(76)$ \\
No & $33.3(24)$ \\
Total & 100.0 \\
Reasons why parents are right to accord more privileges to boys & \\
An Acceptable Tradition & $58.3(61)$ \\
Ordained by God & $41.7(39)$ \\
Total & 100.0 \\
Feelings when parents show preferences to boys & \\
Don't feel threatened/Unhappy & $86.2(91)$ \\
Feel neglected/unwanted & $13.8(9)$ \\
Total & 100.0 \\
\hline
\end{tabular}

Source: Field Survey, 2016

Table 5 displays the perception of the girl-child towards household discriminatory practices. When asked if parents were right to accord more privileges and preferences to boy- children over girl children about 67 percent said "yes". When further asked about the reasons why it was right to give more privileges and opportunities to boy-children 58.3 percent said it was acceptable traditionally and 41.7 percent it was ordained by God. With regard to how they felt when parents accorded preferential treatment and privileges to the boy-child 86.2 percent said they did not feel threatened or unhappy and only 13.8 percent said they felt neglected or unwanted.

\section{Discussion}

The findings of this study revealed that (i) early marriage impedes girl-child education(ii) that early pregnancy is a hindrance to girl-child education(iii) that girl-child education is negatively affected by the belief that if a woman is very educated, she will dominate her husband(iv)and that misunderstanding of the position of Islam on the education of girls impedes girl-child education especially in Northern Nigeria. These findings are consistent with Offorma (2009), Anyanwu,(1995), Igube,(2004) and Indabawa (2004) who had earlier and rightly observed that the belief that education makes women to look down on men negatively impacts on female education and that old customs, traditions, caste systems, rural community and wrongly understood religious doctrines have denied female children quality formal education.

The study further revealed that girl-child education is inhibited by some parents' belief that female children are less competent than male children and less worthy to be given formal education; that the cultural belief that the kitchen is the office of a woman, the highest and best place a woman can function impedes girl-child education and that the belief among some cultural groups that it is a taboo for parents to have an intimate discussion on human sexuality with their children has a way of inhibiting the educational aspirations of the girl-child. These findings are in agreement with the opinions of Indabawa, (2004), Aderinto (1999) and Coetzee, (2001) that there is a cultural subjugation of the girl-child to the boy-child, and that the society does not view the capacities and potentials of the woman beyond the kitchen.

Lastly, the study also revealed that the belief that holds sway among some cultural groups that domestic chores are the basic responsibilities of female children is an inhibition to girl-child education; that some parents do not invest in the education of their female children because they believe they will not benefit from it, and that the notion by some parents that grown up female children are to cater for their financial needs has a way of negatively impacting on the educational aspirations of female children. These findings are consistent with the findings of several authors that gendered domestic duties and the fear of not benefiting from the investment on the education of girl-children inhibit girl-child education (Coetzee, 2001). 


\section{Conclusion}

The study has so far provided new insights on the socio-cultural factors and practices affecting the girl-child among the Annang people. The results indicate that, household discriminatory practices such as access to education, domestic work assignment and the enforcement of restrictive food taboos, limits the capacities and empowerment of the girl-child. This study has affirmed the fact that household discriminatory behaviour towards the girl-child is embedded within specific social relations and cultural contexts which means that household discriminatory behaviour are shaped by social and power relations at the household level, conception of gender roles, gender socialization, cultural construction of girlhood, traditional practices, gender stereotypes, son preference, household decision-making and individual characteristics such as place of residence, education and religious affiliations.

Thus, there is the need for concerted effort by individuals, communities, non-governmental organizations and the government to put in place measures and policies that will help in addressing the deep-rooted socio-cultural factors and practices that engender household discriminatory practices towards the girl-child among the Annang people.

\section{Recommendations}

Based on the major findings of the study, the following recommendations are made:

1. Mass-Media campaigns, community mobilization and sensitization should be embarked upon by the State, LGAs, and NGOs with the support of traditional and religious leaders to address the socio-cultural barriers and harmful traditional practices that tended to limit the empowerment of the girl-child.

2. The need for national and state data bank on various aspects of the girl-child's developmental needs should be created, with a view to strategically addressing and mainstreaming them into the national development plans.

3. A holistic approach should be adopted at all levels of government to address the problems of accessing education by providing girl-friendly schools and ensuring that pregnant adolescent girl-child and adolescent mothers continue and complete their education.

4. Specific media programmes and advocacy programmes should promote inter-generational dialogue, particularly between mothers and girl-children, on the one hand, and fathers and boy-children on the other, with the view of breaking the vicious cycle of household discriminatory practices by developing positive images of girl-children and encouraging gender equality at the household levels.

5. The State should ensure the enforcement of the Child Rights Act of 2003 in order to ensure the protection of the girl-child from all forms of discriminatory practices. Enforcement of the Act once passed should be seen as a priority in the state, such as enforcing the female age at marriage of 18 years.

6. Government should see to the opening up of the hinterland and cultural enclaves as a priority by providing roads, schools, microcredit etc all of which are agents of modernization. The sighting of firms and medium scale industries in such places by government and private investors would serve to create formal employment and modern lifestyles that would constitute an assault to traditional practices, and ultimately lead to the demise of discrimination against the girl-child.

\section{Acknowledgements}

We wish to acknowledge the support and contributions of Paul Udoh, Excel Ofofon Etim, and Celestine Odogwu who served as field research assistants and also assisted in sorting and analyzing the data collected.

\section{References}

Abdullahi, B. H. (2000). Gender, and Patriarchy. Women and the Law in South Africa Changing Families, Changing Laws. Working paper No 9. Harare; WLSA.

Aderinto, A. A. (1999). The girl-child situation in South Western Nigeria: An assessment. Journal of Social Sciences: Interdisciplinary Reflection of Contemporary Society, 3(1-2), 97-108.

Aina, F. E., \& Abdullah, E. J. (1995). Addressing the Cultural Impediments to Girl- Child Education in Nigeria, in Omamor, A. P., Osinulu, C., \& Idowu, A. (eds) (1995). The Survival of the Girl-Child: Problems and Prospects. Lagos: Nigerian Association of University Women.

Alabi, T., \& Alabi, O. S. (2012). Child trafficking amongst urban poor in Lagos.

Alabi, T., Bahal, M. K., \& Alabi, O. S. (2014). Child labour amongst urban poor in Lagos and Abuja. Journal of Sustainable Development in Africa, 3(2), 76-84.

Alcoff, L. (1990). Feminist Politics and Foucault. Albany, New York: Suny Press.

Anyanwu, S. O. (1995). The Girl-Child: Problems and Survival in the Nigerian Context. Scandinavian Journal of 
Development Alternatives, 14(1-2), 85-105.

Arokiasamy, P. (2007). Sex Ratio at Birth and Excess Female Child Mortality in India: Trends, Differentials and Regional Patterns in Attané, I and C. Z Guilmoto (eds). Watering the Neighbour's Garden: The Growing Demographic Female Deficit in Asia. Paris: Committee for International Cooperation in National Research in Demography (CICRED), 49-72.

Babbie, E. (2007). The Practice of Social Research. $11^{\text {th }}$ ed. Belmont: CA: Thomson Higher Education.

Bordo, S. (1993). Unbearable Weight: Feminism, Western Culture, and the Body. Berkeley: University of California Press.

Bradley, C., \& Moore, C. C. (1996). Sexual Divisions of Labour. In Levinson, D and Ember, M. (eds) Encyclopaedia of Cultural Anthropology. New York: Henry Holt and Co., 4, 1168-1173.

Cochran, W. G. (1997). Sampling Techniques. New York: John Wiley and Sons.

Coetzee, D. (2001). South African Education and the Ideology of Patriarchy. South African Journal of Education, 21(4), 300-304.

Conference of the UniversityWOMENNE of Africa Heldin Lagos on 16th-19th July.

Ferraro, G. (2008). Cultural Anthropology: An Applied Perspective. $7^{\text {th }}$ ed. Belmont: C.A: Thomson Higher Education

Fisho-Orideji, D. (2001). The Girl-child: Developing the Potentials of Girl-child a National Challenge'

Gaidzwanwa, A.G. (1992). Women and Human Rights. Social Change: Issues and Perspectives, 25(2-3), 3-17.

Giddens, A., Duneier, M., \& Appelbaum, R. (2005). Introduction to Sociology. $5^{\text {th }}$ ed. New York: Norton.

Igube, R. B. (2004). Gender Security and Advancement: The Case of Inequality and Inequity.

Indabawa, S. A. (2004). On Some Socio-Cultural Determinants of Girls' Involvement in Education in Nigeria. The African Symposium, 4(1). Retrieved from http://www.ncsu.edu/aem/TAS4.1/TAS4.1.pdf

Isiugo-Abanihe, U.C. (2002). Quantitative Research Technique. Isiugo-Abanihe, U.C, Isamah, A.N and Adesina, J.O (eds). Currents and Perspectives in Sociology. Lagos; Malthouse Press, 52-72.

Janssen, D. F. (2006). Girlhood Studies. A Bibliographic Exploration. Retrieved from http://www.growingupsexually.tik. Journal of Peace, Gender and Development, 2(3) March 2012. Journal of Peace, Gender and Development, 2(3) March 2012.

Juitting, J., \& Morrisson, C. (2005). Culture, Gender and Growth. Policy Insights, No 15, October 2005.Retrieved from https://doi.org/10.1787/246727453385

Jutting, J., \& Morrisson, C. (2005). Changing Social Institutions to Improve the Status of Women in Developing Countries. Policy Brief No. 27. OECD Development Centre. https://doi.org/10.1787/518103673332

Kameri-Mbote, P. (2005). The land has its Owners! Gender Issues in Land Tenure under Customary Law in Kenya. International Environmental Law research Centre. IELRC Working Paper 2005-9. Retrieved from http://www.ielec.org/content/wo509.pdf

Kapur, P. (1995). Girl-Child Abuse: Violation of Her Human Rights. Social Change: Issues and Perspectives, 25(2-3), 3-17.

Koohi-Kamali, F. (2008). Intra-household Inequality and Child Gender Bais in Ethiopia. World Bank Policy Research Working Paper, 4755.

Li, S., Wei, X., Jiang, Q., \& Feldman, M. W. (2007). Imbalanced Sex Ratio at Birth and Female Child Survival in China: Issues and Prospects. Watering the Neigbour's Garden: The Growing Demographic Deficit in Asia. Paris Committee for International Cooperation in National Research in Demography (CICRED), 25-48.

Lundberg, S. (2005). Sons, Daughters, and Parental Behaviour. https://doi.org/10.1093/oxrep/gri020

McFadden, P. (1994). Gender, Power, and Patriarchy. Women and Law in South Africa Changing Families, Changing Laws. Working paper No 9. Harare; WLSA.

Meek, C. K. (1931). Tribal Studies in Northern Nigeria. London: Kegan Paul and Co Ltd.

Moletsane, R., Mitchell, C., Smith, A., \& Chisholm, L. (2008). Methodologies for Mapping a South African Girlhood in the Age of AIDS. Amsterdam: Sense Publishers.

Moletsane, R., Mitchell, C., Smith, A., \& Chisholm, L. (2008). Methodologies for Mapping a South African Girlhood in the Age of AIDS. Amsterdam: Sense Publishers. 
Offorma, G. C. (2008). The Boy-child-education in the South-eastern States of Nigeria

Offorma, G. C. (2009). The Girl-child-education in Africa. Keynote Address Presented at the

Ogidi, D. P. (1997). The Girl-Child Situation in Niger State: Determinants, Pattern and Perceptions. An Unpublished Master Thesis, Sociology Department, University of Ibadan.

Oyewunmi, O. A. (2004). Socio-Cultural Determinants of Girls' Involvement in Education in Nigeria. The African Symposium, 4(1). Retrieved from http://www.ncsu.edu/aem/TAS4.1/TAS4.1.pdf

Pande, R., \& Malhotra, A. (2006). Son Preference and Daughter Neglect in India: What Happens to Living Girls. Washington D. C. International Centre for Research on Women. Retrieved from. http;//www.icrw.org/.../son-preference-neglect-India. Paper Presented at the Round Table Discourse by Higher Link Educational Programme, The British Council, Change Managers International, University of Abuja, Abuja 8th march, 2004.

Plan International (2007). Because I am a Girl: The State of the World's Girls 2007. Retrieved fromhttp://www.planinternational.org/files/global/publicatios/campaigns/becauseiamagirl.pdf

Pradhan, B. (2001). "Framework for Integrating Socio-Cultural Research unto UNFPA Population and Reproductive Health Programmes."pp 15-20 UNFPA. 2001. Integrating Socio-Cultural Research into Population and Reproductive Health Programmes. Workshop Report, Kathmandu, Nepal November 26-December, 2001. Problems and Prospects. Paper Presented at the Convention of the Unity Schools Old Students Association (USOSA), held at Dannic Hotel, Enugu.

Punalekar, S. P. (1995). Gender, Class and Culture: Situation of Girl Children in India, in Devasia, V. V. (ed.) Girl-Child in India, New Delhi: Ashish Publishing House.

Randall, V. (2010). Feminism, in March, D. and Stoker, G. (eds) Theory and Methods in Political Science $3^{\text {rd }}$ ed. Hampshire. Palgrave Macmillan.

Reddy, V. (2009) .Turning Sugar and Spice on its Head: Recent Research on the Gendered Meanings within Girlhood Studies. Open Forum. http://www.hsrc.ac.za/Document-3818.phtml

Ritzer, G., \& Goodman, D. J. (2003). Sociological Theory. $6^{\text {th }}$ ed. New York: McGraw-Hill.

Rowe, K. (2002). The Measurement of Latent and Composite Variables from Multiple Items or Indicators: Applications in Performance Indicator Systems". Background Paper prepared for Keynote Address for the Royal Melbourne Institute of Technology Statistics Seminar Series October11, 2002.Retrieved from http://www.research.acer.edu.au/learning_process/12

Rufai, R. A., \& Ogidi, D. P. (2006). An Appraisal of Best Practices in Girls' Education Initiatives in Nigeria. Technical Report. Child Development Department, Federal Ministry of Women Affairs \& Child Development, Abuja: Nigeria.

Scanzoni, J., \& Szinovacz, (1984). Family Decision Making: A Development Sex Role Model California: Sage Publication Inc.

Schaefer, R. T. (2008). Sociology. $11^{\text {th }}$ ed. New York: McGraw-Hill.

Udo, E. U. (1983). The History of the Annang People, Calabar, Nigeria. Apcon Press Ltd.

Udondata, J., \& Idem-Agozino, U. (2001). Annang Orthography, Uyo, Scholars Press.

Umoh, E. (2004). Annang Map with Boundaries, Plano TX. USA

United Nations (2002). Fertility behaviour in the context of development: evidence from the world fertility survey. P0pulation studies no.150 ST/ESA/SER.A/100New York. 


\section{Appendix}

Sex Distribution of Respondents

\begin{tabular}{lll}
\hline Sex & Frequency & Percentage \% \\
Male & 21 & 17.6 \\
Female & 98 & 82.4 \\
Total & 119 & 100.0 \\
\hline
\end{tabular}

Source: field survey, 2016

Age distribution of Respondents

Source: field survey, 2016

\begin{tabular}{lll}
\hline Age & Frequency & Percentage \% \\
$16-20$ & 2 & 1.7 \\
$21-25$ & 19 & 16.0 \\
$26-30$ & 39 & 32.8 \\
$31-35$ & 43 & 36.1 \\
36 and above & 16 & 13.4 \\
Total & 119 & 100.0 \\
\hline
\end{tabular}

Respondents Educational Attainment

\begin{tabular}{lll}
\hline Level of education & Frequency & Percentage \% \\
Primary & 11 & 9.2 \\
Secondary & 72 & 59.6 \\
Tertiary & 7 & 14.3 \\
None & 29 & 24.4 \\
Total & 119 & 100.0 \\
\hline
\end{tabular}

Source: Field survey 2016

Respondents Marital Status

\begin{tabular}{lll}
\hline Marital status & Frequency & Percentage \% \\
Married & 20 & 15.4 \\
Single & 97 & 81.5 \\
Divorce/separated & 2 & 3.0 \\
Total & 119 & 100.0 \\
\hline
\end{tabular}

Source: Field survey 2016

\section{$(\mathrm{cc})$ EY}

This work is licensed under a Creative Commons Attribution 3.0 License. 